\title{
Homogeneity of urban biotopes and similarity of landscape design language in former colonial cities
}

\author{
MARIA E. IGNATIEVA AND GLENN H. STEWART
}

\section{Introduction}

When the Anglo settlers set out to establish colonies in the United States, Canada, Australia and New Zealand they were attempting to create a 'new England', a purified British society transplanted to another land. These countries have a lot in common in history, demography and interconnections: they are Anglo 'colonies of settlement' (unlike 'colonies of Empire') where Europeans dispossessed and almost exterminated the earlier inhabitants (Diamond, 1997; Dunlap, 1999). In the case of the United States and Canada there were also other significant European settlement influences such as French, German, Dutch and Spanish. In the nineteenth century the settlers made themselves at home in these new lands by making it like home. They used European plants and animals and tools of industrial civilisation to transform the countryside with a speed and thoroughness never seen before and on a scale that has never been repeated. The destruction of native ecosystems was a central process, eclipsed only by the subsequent enthusiasm for importing mammals and birds for sentiment and sport. Both had dire biological and social consequences.

Changing the land was not an event but a process characterised by a set of actions that created a suite of landscapes. The transformation was most complete around settler homes. European grasses spread to picket fences, roses and lilacs bloomed in North American yards, primroses and other English flowers by Australian and New Zealand homes. In parks from New York to Sydney people

Ecology of Cities and Towns: A Comparative Approach, ed. Mark J. McDonnell, Amy K. Hahs and Jürgen H. Breuste. Published by Cambridge University Press. (C) Cambridge University Press 2009. 
walked on European grass growing in imitation English meadows, and the commonest birds they saw were starlings, pigeons and English sparrows. In rural areas, European crops filled the fields and European weeds the roadside ditches, but some native species persisted (Cronon, 2003). New habitats were created and the wild changed as plants and feral animals spread before the settlers.

After a lengthy period of redoing their new lands, governments by the late eighteenth century began to establish more systematic efforts in the service of 'empire'. They established experimental gardens in the tropics and at home for botanical studies and as a source of novelties for the gardens. They tested new species and shifted promising ones to their new lands. With the increased speed and volume of shipping by the mid nineteenth century commercial gardeners were stocking British greenhouses with tropical plants and sending British flowers to homesick colonials in the antipodes.

By the late nineteenth century settlers had formed societies to 'improve' their countries by stocking them with 'useful and beautiful' plants and animals. These societies concentrated on species from 'home' but in some instances also imported plants and animals from around the world. In New Zealand for example, more than a hundred species of birds and over 30 species of mammals, including deer, possums and wallabies, were introduced (Veblen and Stewart, 1982). Within a generation this fad had passed, but seldom have so few done so much over so large an area with so little effort or understanding. In the end of the nineteenth and the beginning of the twentieth centuries many former colonial cities experienced the 'beautification' movement based on a contemporary understanding of European forms and the monumental idioms of city planning, architecture and planting design.

In the twentieth century there arose a new appreciation of nature and along with it, the conservation movement - the beginning of searching for each country's particular ecological identity (Worster, 1977). Settlers began to examine seriously what effects the land had on them and to incorporate the land into their culture. Conspicuous or emblematic plants and animals became national symbols - the kiwi in New Zealand and the kangaroo in Australia are classic examples. Landscape paintings, nature literature, outdoor recreation and nature education became an integral part of urban middle-class leisure. Governments took new steps to protect nature, setting aside rural or wilderness areas for recreation and protection. This culminated in the strong environmental movements of the 1960s and 1970s when ecological knowledge became a cornerstone of the conservation movement.

The unique ecological identity of the former colonies therefore reflects similarities and differences in the cultural, historical and ecological aspects of the landscape. This is particularly obvious in urban environments. There has been a 
strong European influence in the way that cities were planned and the way in which they developed. The objective of this chapter is to explore some important principles of urban planning structure (grid system, downtown and suburban sprawl) and different landscape architecture styles (Capability Brown, Picturesque, Gardenesque and 'Wild' Garden), and to look at the peculiarities of using the same plant materials in parks and gardens. These principles are the main reasons behind the phenomena of homogenisation of urban environments and the creation of similar urban habitats in former colonial cities (creation of lawns, hedges, flower beds, walls, pavement cracks, etc.). These similarities of urban habitats can be an excellent starting point in initiations of comparative analysis in different cities and towns. This chapter also explores some practical planting design solutions ('freedom lawns', 'go wild', 'plant signatures' and indigenous gardens) that break the homogeneity of urban environments and help to create identity of cities. We use as examples cities in the northeastern United States, Australia (mostly Melbourne, Sydney and Adelaide) and New Zealand. We use the word 'homogeneity' in its broader meaning as consisting of similar design and plant materials that are similar to each other.

\section{Starting points}

Native landscapes of the northeastern United States prior to European colonisation were primarily forested landscapes (mostly deciduous forests). Native Americans cultivated many plants, including beans and squash, and they cleared some forests for agriculture (Cronon, 2003). In appearance and plant composition (and even fauna) European and northeastern landscapes had much in common. Both landscapes were influenced, and in many cases shaped, by the most recent glaciations and both were clothed with deciduous forests. The landscapes were much 'wilder looking' to Europeans because back at home there were few native forests remaining. On the other hand in the northeastern United States, Europeans could see not only a forested landscape with familiar trees but also familiar mammals such as deer, bear, wolf and fox.

Compared with this, native Australian and New Zealand landscapes looked completely different to the colonists. In New Zealand they were confronted with an essentially forested landscape (apart from the eastern side of the South Island) with an unfamiliar complement of plants and animals. The dramatic and breathtaking landscape ranged from boiling mud pools, volcanoes and geysers in the north to soaring mountains, primeval forests and glaciers in the south. Apart from two species of native bats there were no terrestrial land mammals and a highly endemic avifauna, many of which were flightless. In an attempt to make their new country 'more like home' the colonists voraciously cleared the forests and 
converted the land to pasture. That, and the introduction of familiar mammals, dramatically changed the landscape. In Australia, settlers found a hot, dry and unforgiving land (Flannery, 1999) - tropical forests in the north, eucalyptus forests for miles and miles, and endless deserts in the middle, full of strange and wonderful but utterly unfamiliar animals. As in New Zealand, cities and towns sprang up, mainly near the coast, and forests were rapidly converted to pasture.

European settlers applied to these completely different native landscapes on the other side of the globe the exact same principles of urban design and landuse practice, landscape and planting that they had practised in Europe.

\section{The European influence}

Urban planning principles

All human landscapes reflect cultural peculiarities in some way. When Europeans arrived in the New World countries they brought their own architectural styles for buildings and patterns to follow in urban planning. Even though American, Australian and New Zealand cities were established at different times, they all exhibit some similarity in the history of their development. All new towns and cities had mainly European design patterns with some peculiarities related to differences in climate, topography, politics and their economic situation.

The grid system

Initially, all colonial settlements explored a regular grid planning structure. The grid system is a logical way to survey land in straight lines, whether for a township or an urban lot. The grid system gave the city functional efficiency and was ideal for the equal distribution of land or easy parcelling and selling of real estate. Historically the urban grid served two main purposes. The first was to facilitate orderly settlement and colonisation in a broad sense. The second was its use as an instrument of modernisation and as a contrast to what was not as orderly. One of the first large US cities planned using a grid system was Philadelphia. The grid system was the most efficient way of using space for development where topography was non-limiting and was supposed to encourage economic development (Homberger, 1994). Syracuse, New York, founded around the 1840s, also demonstrated a classical grid structure intersected by the Erie Canal (Fig. 23.1a).

In New Zealand and Australia many towns were designed in Great Britain using the regular grid system as a model. For example, in the Edward Jollie plan of Christchurch a classical rectangular grid can be easily recognised (Fig. 23.1b). An early plan of Melbourne also shows a rectangular grid of streets one mile by half a mile (Fig. 23.1c). Adelaide was started as a simple grid that covered one square mile and was surrounded by parkland. 

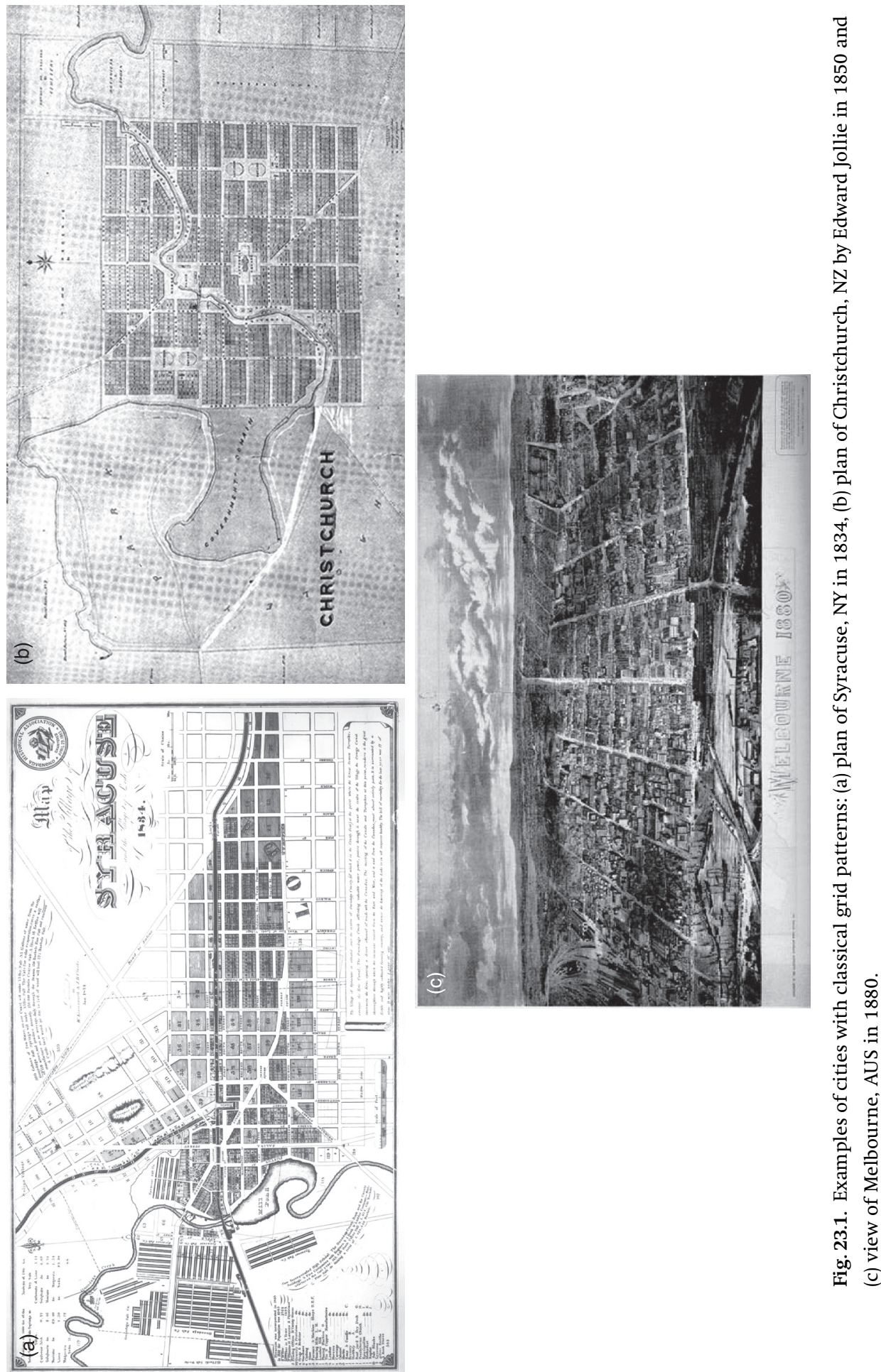


\section{Downtown}

The next influential chapter in the development of urban planning of colonial cities was a crystallisation of commercial urban cores in the end of the nineteenth and the first part of the twentieth centuries. Development of downtowns was driven by growing demand for limited amounts of good commercial real estate and by opportunities provided by modern technology. Earlier towns were transformed into intense and more exclusive settlements with singlepurpose areas established, such as financial, shopping and administrative districts (Kostof, 1992). Densely urbanised areas with skyscrapers expressed the new assertiveness of technology and the modern urban spirit. The panorama of New York's Manhattan district started to be a world-famous symbol of American cities (Fig. 23.2a). This symbol 'served American national pride', it was also a symbol of 'power, energy, daring, and sophistication' (Meinig, 1979). This American pattern was later mirrored in Australian cities (Melbourne downtown, Fig. 23.2b), New Zealand (Wellington downtown, Fig. 23.2c) and even in Europe (La Defence in Paris and London's Canary Wharf; Kostof, 1992).

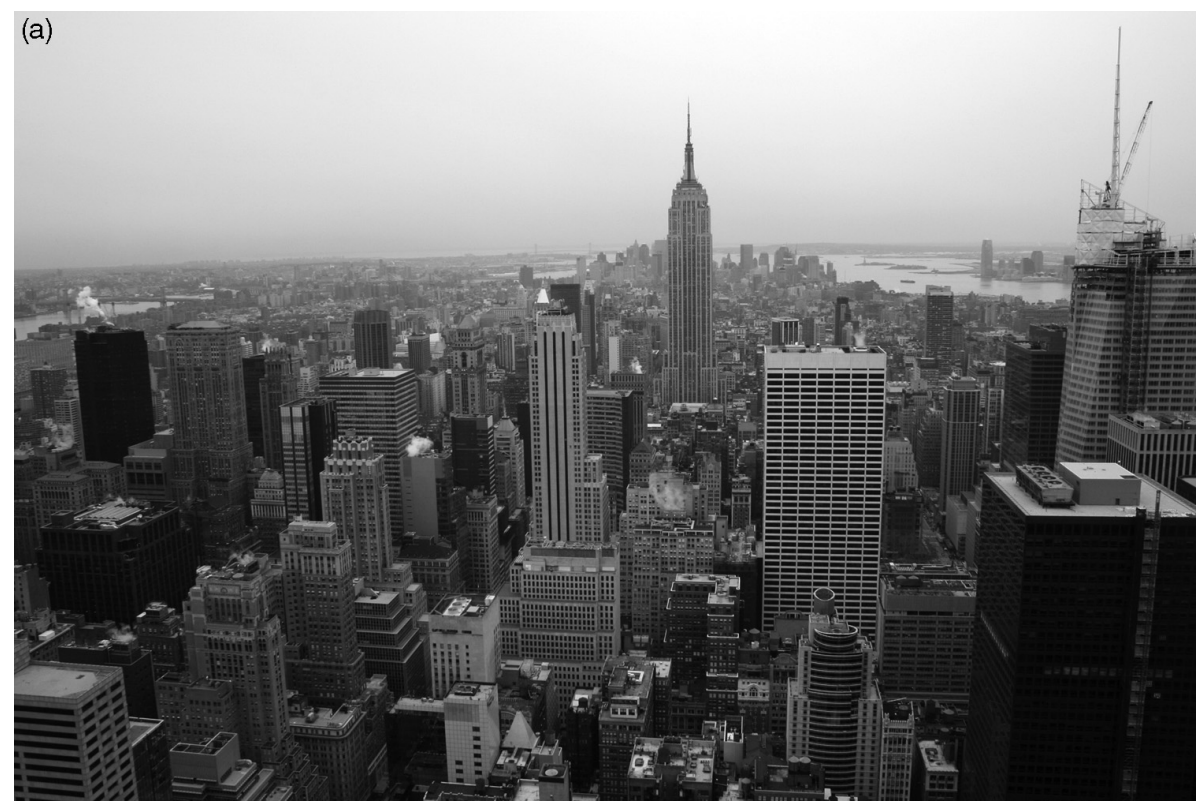

Fig. 23.2. Panorama views of three former colonial cities illustrating their roles as symbols of urban prosperity, technology and power: (a) New York's Manhattan district as world-famous symbol of American cities, (b) downtown Melbourne, AUS and (c) downtown Wellington, NZ. 


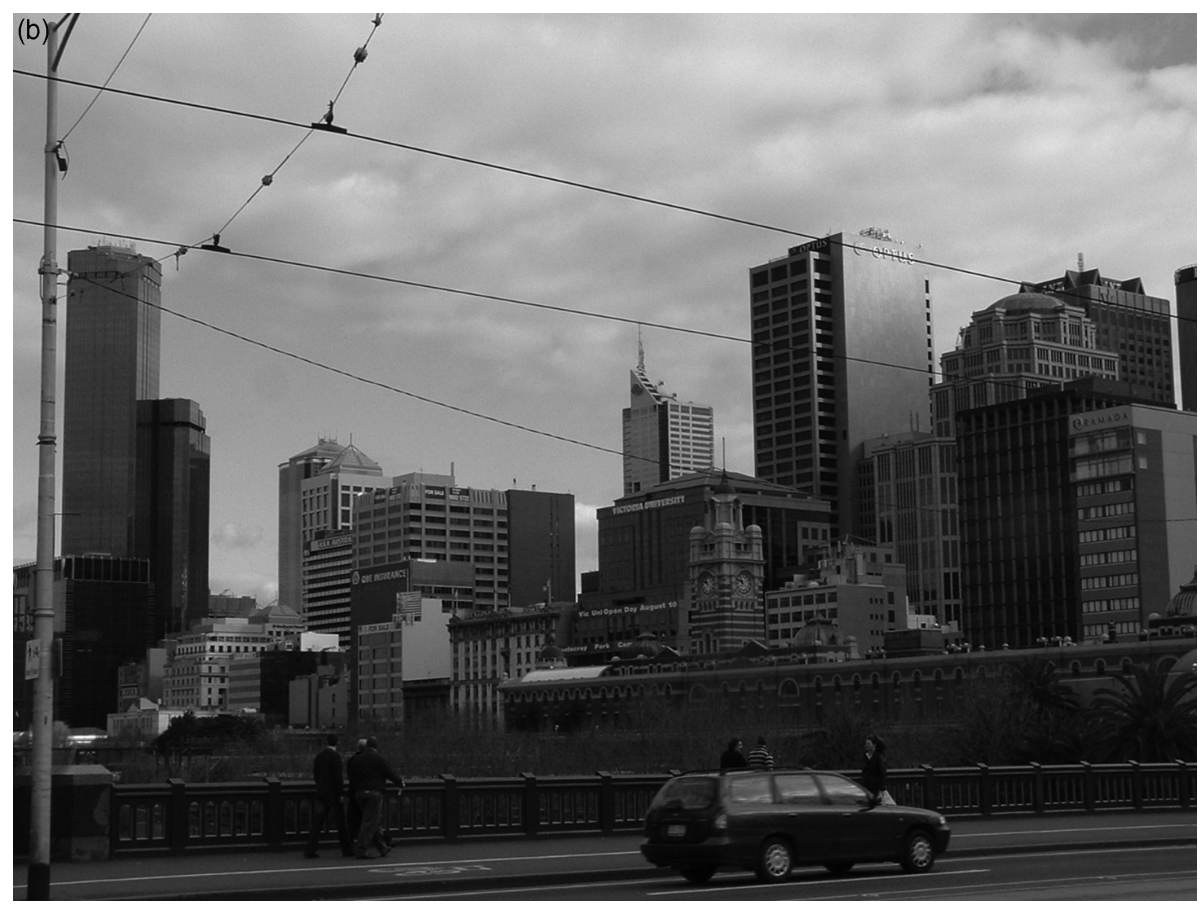

(c)

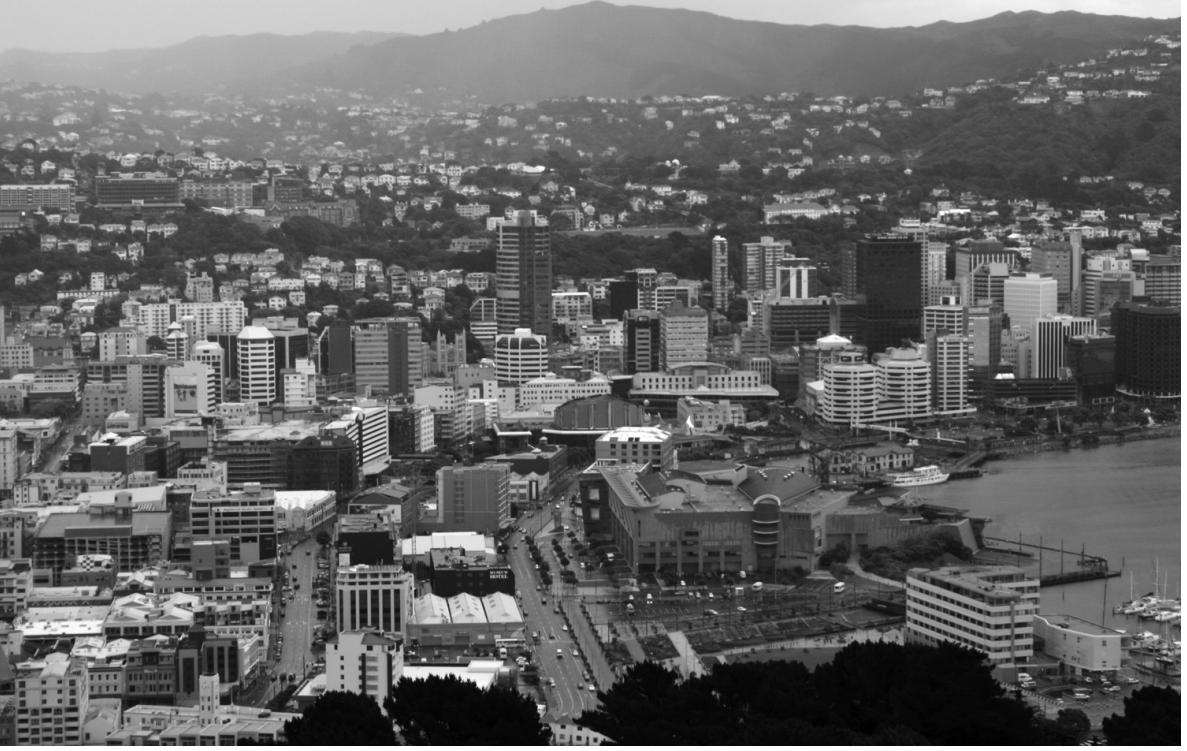

Fig. 23.2. (cont.) 
Suburbia

The third most influential urban planning element that has driven the development of all former colonial cities has been suburbia. The modern suburb is the result of an era of industrialisation and fast transportation. By the end of the nineteenth century a new pattern of residential settlement for commuters developed in Europe and the United States. Development of suburbs always reflected differences in local culture, banking systems, transportation, building technique and administrative authority. There are two major types of suburbia: a diffuse patchwork of detached houses, or high-density apartment blocks with open areas (Kostof, 1992). For example, English Georgian suburbs developed a pattern with rows of identical very closely attached houses. High density apartment blocks were a very common type of suburbia in Western and Eastern Europe. Rows of identical attached single-family terraced houses with tiny gardens have also been very influential in US seaboard cities (e.g. Philadelphia, New York, Baltimore, Boston, San Francisco). There are only a few surviving examples of this type of suburb in the USA.

By the beginning of the twentieth century, suburbia characterised by detached houses started to become most influential in the USA and later in Australian and New Zealand cities. The reason for the popularity of this type of suburbia in the USA was the right of landowners to develop their properties as they wanted. In the period after World War II, the USA experienced an unprecedented migration to the suburbs. Between 1946 and 1956 about 97\% of all new single-family dwellings were detached and surrounded on every side by their own plots (Jackson, 1985). Typical lot sizes were relatively uniform around the country (averaging $0.1-0.2$ acre or 810 to 405 square metres). These suburbs, which began as early as the 1930s in the United States, became completely automobile dependent, a condition exaggerated by Eisenhower's Interstate Defence Highway Act of 1956.

Another very important feature of American post-war suburbs was an architectural similarity. It was a result of reducing the design fees by simplifying the production methods and design solutions. After World War II, because of these mass-production techniques, government-financed high wages and low interest rates, it was easier to buy a new house in suburbia than to reinvest in central city properties (Jackson, 1985).

Suburbia effectively grew in all Australian and New Zealand cities in the post-war years. There are some differences of course in the design solution of the individual plots and residential architecture, but ideologically suburbia's structure was very similar in these countries to that in the United States (Fig. 23.3a, b and c). One of the reasons for sharing the US experience of suburbia in Australia, New Zealand and Canada is a strong frontier tradition of small populations, and a British cultural dislike of cities (Jackson, 1985). 


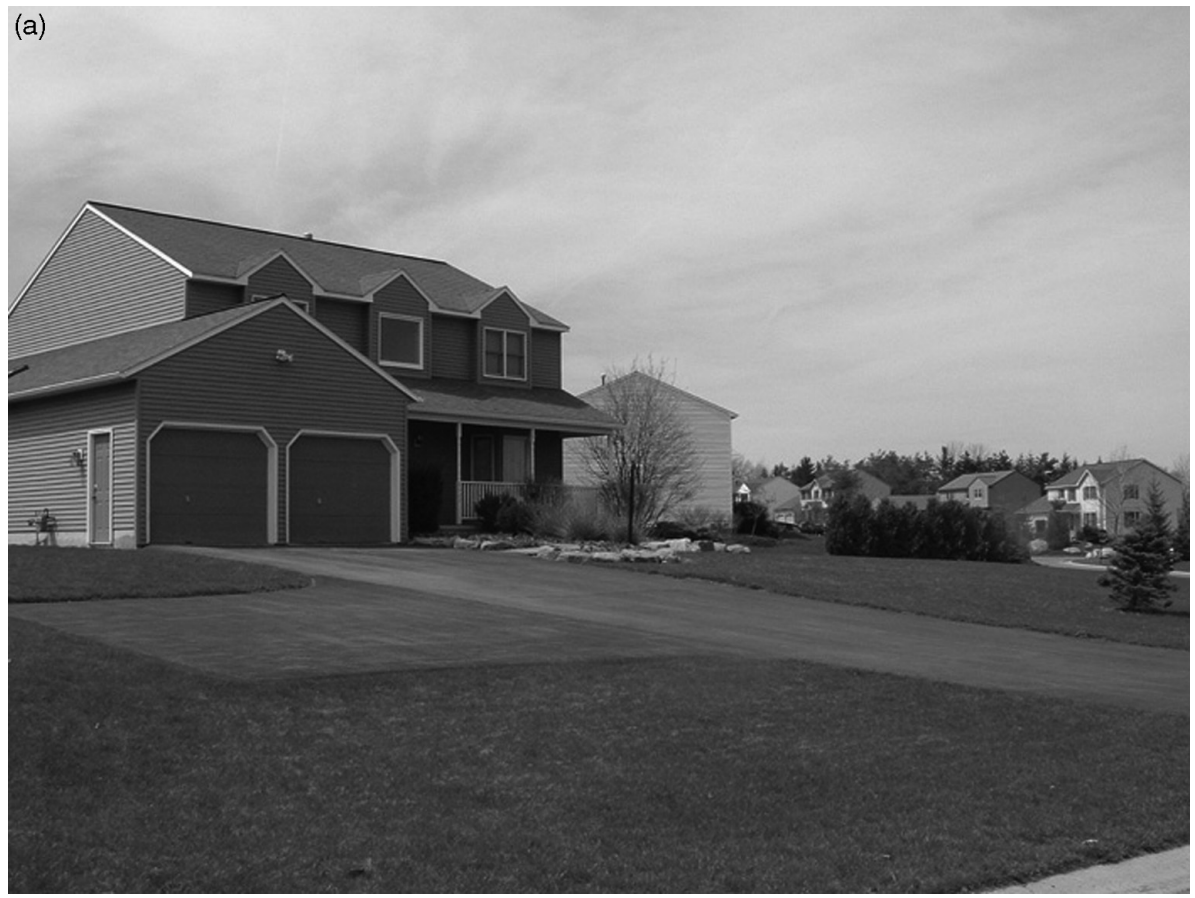

(b)

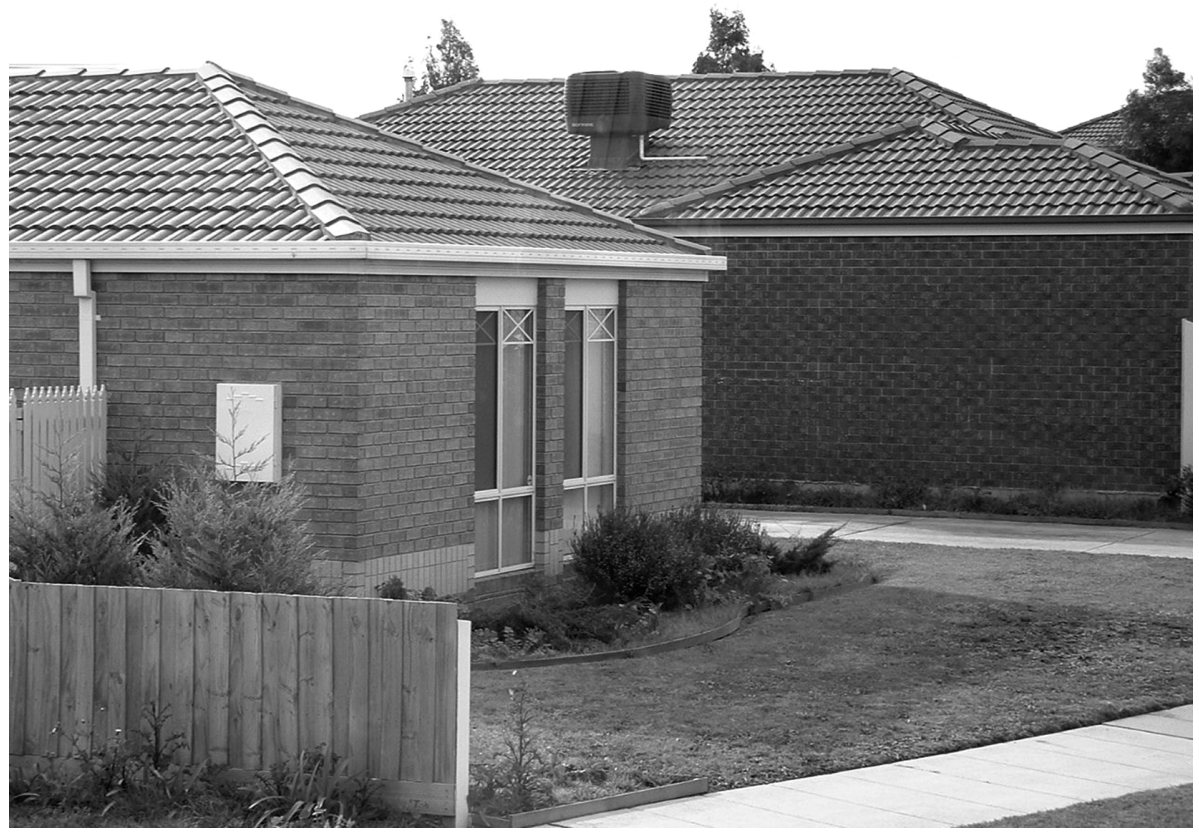

Fig. 23.3. Examples of suburban development showing similarity in the ideological structure of suburban life: (a) Syracuse, New York in 2003, (b) Melbourne, Australia in 2003 and (c) Christchurch, New Zealand in 1998. 


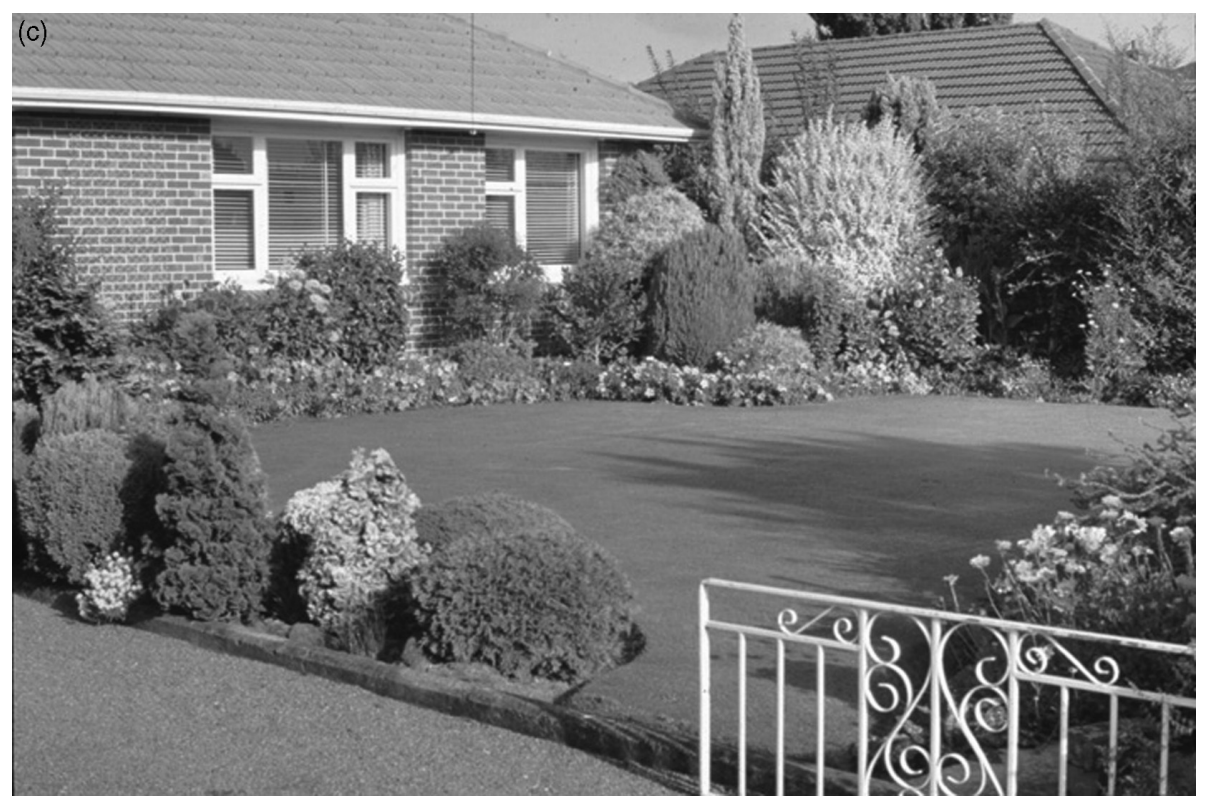

Fig. 23.3. (cont.)

Urban renewal

Urban renewal in the United States, Australia and New Zealand was equivalent to post-war reconstruction in Europe. It took place mainly in downtown areas in the 1950s and 1960s. Many places were completely cleared of structures and then re-developed. It was viewed as a way to install modern components in American downtowns (Kostof, 1992). The same tendencies can be seen in many Australian and New Zealand cities. Large buildings, tall monolithic structures (new skyscrapers), parking garages and huge parking lots, and new apartment houses transformed the traditional downtown colonial grid. However, it is important to note that many cities have historic buildings and districts that were preserved.

As a result of similar historical development of urban planning in cities in the USA, Australia and New Zealand, there are striking similarities in urban planning structures, such as the original simplified grid pattern, modern downtown, suburban sprawl and extensive transportation systems. The similarity in urban planning structure is one of the main reasons for the creation of similar urban habitats such as paved areas, roads, building walls, garden and park lawns, street planting and parking lots.

\section{Landscape architecture styles}

Landscape design styles were another very important part of European 'borrowed' baggage that arrived in the New World colonies. At the end of 
the eighteenth century and the beginning of the nineteenth century the most influential was 'Capability' Brown who was followed by the Picturesque style. Lancelot 'Capability' Brown (1716-83) edited nature and created an aesthetically 'perfect' landscape. The topography was shaped in the form of a series of gentle convex and concave curves. Trees were planted in groves, groups or belts. An emerald-green flowing lawn was one of the essential composition elements. He used only native deciduous trees (e.g. Quercus robur, Tilia cordata, Fagus sylvatica, Ulmus laevis, Acer platanoides, Acer pseudoplatanus, Fraxinus excelsior) and a few evergreen tree species. Brown's gardens were simply a productive working landscape arranged to be beautiful (Rogers, 2001).

In the last decade of the nineteenth century the principle of deriving landscapes from pictures was to be called 'Picturesque'. Advocates desired to add 'the bold roughness of nature' and suggested appreciation of wild nature as seen through the filter of art. William Gilpin, one of the main ideologists of the Picturesque style, promoted 'bold nature' by encouraging conversion of lawns to rugged oak woodlands, complete with wheel tracks, scattered stones and brush-wood. Instead of making landscapes smooth, Gilpin suggested making them rough, and therefore picturesque (Rogers, 2001). The Picturesque style was the most influential as a theoretical source, especially in new colonies. One of the most famous admirers of both Capability Brown and Picturesque was Frederick Law Olmstead, the designer of Central Park in New York City, who created park landscapes that were both pastoral and picturesque. Olmstead strongly believed that the pastoral and picturesque scenery of parks would be instructive to immigrants of the new democratic societies, through a process of scenic enjoyment of predominantly agrarian values (Rogers, 2001). Open spacious lawns with gentle rises and scattered clumps of trees, curvilinear lines of pathways, ponds and lakes all aiming to create scenic views appeared in public parks and gardens. Cities in the United States, New Zealand and Australia were influenced by Capability Brown and Picturesque ideology (Fig. 23.4a and b). Frederick Law Olmsted and the social reformer Charles Loring Brace helped in creating a new vision of suburbia in the USA and other colonial countries.

Suburban yards in former colonial countries also followed this romantic approach with their gently curving paths, irregular groupings of trees and shrubs, and often-rustic pavilions. Many authors see the presence of green lawns in suburban gardens as nostalgia for English motherland gardens. The appearance of sheep, cows, deer and other 'plastic' kitsch culture attributed to the middle-class front lawns in the USA, Australia and New Zealand is also a kind of intuitively nostalgic note on the pastoral English landscape. Especially in the USA the well-manicured yard became a symbol of wealth and social standing.

The Industrial Revolution in Europe in the nineteenth century opened a new era of stylistic diversity. Gardenesque style was opposite to Picturesque and 


\section{(a)}
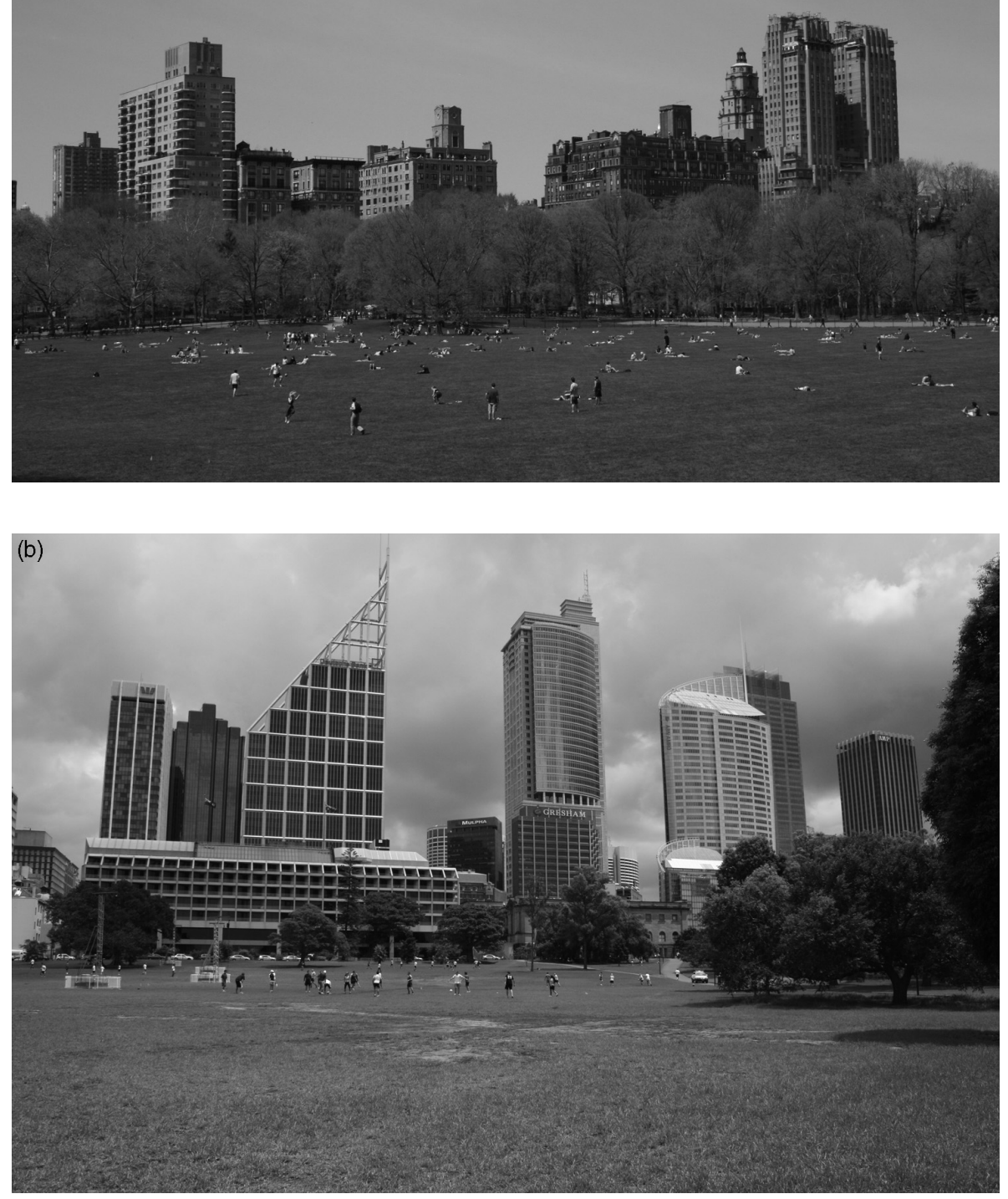

Fig. 23.4. Examples of Capability Brown and Picturesque ideology of gentle curves and open lawns with scattered clumps of trees: (a) Central Park (New York City) and (b) one of Sydney's (Australia) public parks. 
introduced eclecticism of design styles and exoticism - use of new plant species that had just been discovered in different parts of the world. John Claudius Loudon introduced the principle of incorporating exotic species and a display of all plants in a way that would highlight individual species (Rogers, 2001). The Gardenesque approach in landscape design was a very powerful tool of the Victorian ethic of 'improvement'. Victorian gardens actually perpetuated the picturesque approach but used and displayed new exotic plants. The lawn was used as a special display where each plant can 'arrive at perfection' and the quality of plants can be seen especially clearly (Elliott, 1986). Around the 1840s new exotic plants started to be used in the system of 'change-bedding' - very elaborate floral displays planted mainly for temporary seasonal decorative effect. The introduction of the lawn mower in 1830 provided the opportunity to have a manicured lawn-display not only in large private or public parks but also in small gardens.

Capability Brown, Picturesque and Gardenesque styles were actively used in colonial countries. It resulted in the creation of similar types of habitats in public and private parks and gardens: lawns - the leading type - flowerbeds, tree and shrub groups, and groves.

The Edwardian period saw two very influential figures in landscape design. William Robinson introduced the 'Wild Garden' concept, where the garden should highlight natural development and express plant colour, form and growth habit (Zuylen, 1994). He advised the planting of alpine species in small rock gardens, the use of naturalised shrubs and ground covers in woodland parts, and native and exotic bulbs in grass and woodlands. Robinson created gardens where natural processes could be seen and appreciated. Gertrude Jekyll tried to combine the naturalistic approach within the more formal framework in her famous colourful herbaceous borders (Bisgrove, 1992).

Robinson's naturalistic gardens were incorporated in many private and public gardens in England and former colonial cities by using daffodils and bluebells in meadows and woodlands, on riverbanks and in private yards. Diverse or very simplified versions of Jekyll's herbaceous borders can be found in United States, New Zealand and Australian cities (Fig. 23.5).

\section{Planting design}

Classic romantic English parks were based on native broad-leaved trees (e.g. Quercus robur, Tilia cordata, Fagus sylvatica, Ulmus laevis, Acer platanoides, Acer pseudoplatanus, Fraxinus excelsior). There were only a few exotics used for solo planting such as Cedrus libani, Salix babylonica and Populus nigra 'Italica'.

In colonial parks deciduous trees were also essential plant material. For example, in Christchurch parks created in the middle to the end of the 


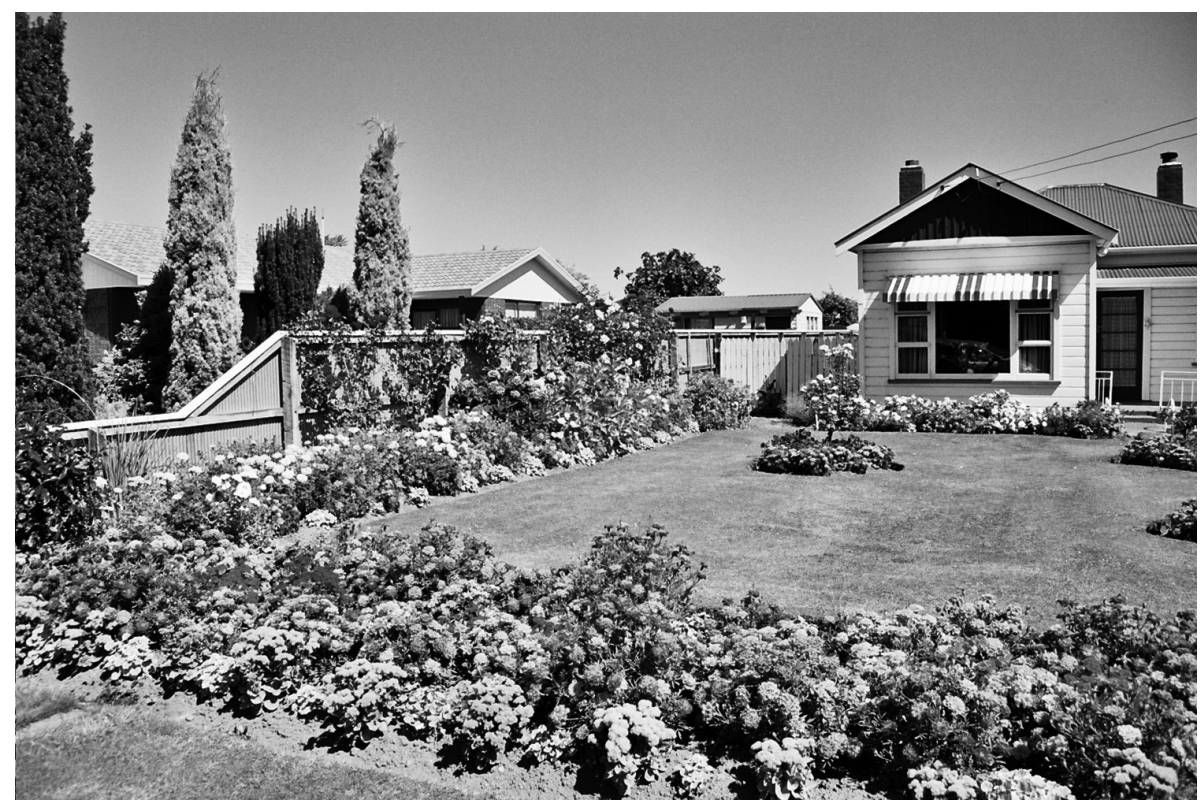

Fig. 23.5. Simplified versions of Jekyll's herbaceous borders in one of the private gardens in Christchurch, New Zealand.

nineteenth century and the beginning of the twentieth century European deciduous trees were dominant. The image of 'the most English city outside England' was created because of wide use of European plants that were essential for Picturesque parks and gardens. In Australia there was a tremendous effort to establish deciduous trees all over the country to provide connections with home and to relieve the monotony of the naturally dull native Melaleuca, Callitris and Eucalyptus species with fresh green in spring and colour in autumn (Bligh, 1980).

In the USA, European deciduous trees were also used, but native deciduous trees such as Acer saccharum, Quercus rubra, Ulmus americana and Fraxinus americana were often planted. Native deciduous American trees were very 'lucky' because of their close resemblance and genetic relationships to European relatives in texture, and in colour, in other words to the general European image.

Gardenesque style introduced to European and colonial parks and gardens a whole range of tropical and subtropical plants from around the world. For carpet beds Central and South American plants such as Tagetes erecta, Tagetes patula, Begonia semperflorens or Ageratum houstonianum were among the favourites. The 'discovery' of the Chinese flora resulted in the appearance in gardens of Chrysanthemum maximum, Dianthus chinensis and Callistephus sinensis.

Chinese and American rhododendrons and azaleas were an excellent 'discovery' for William Robinson's wild garden. Many public parks or private gardens 


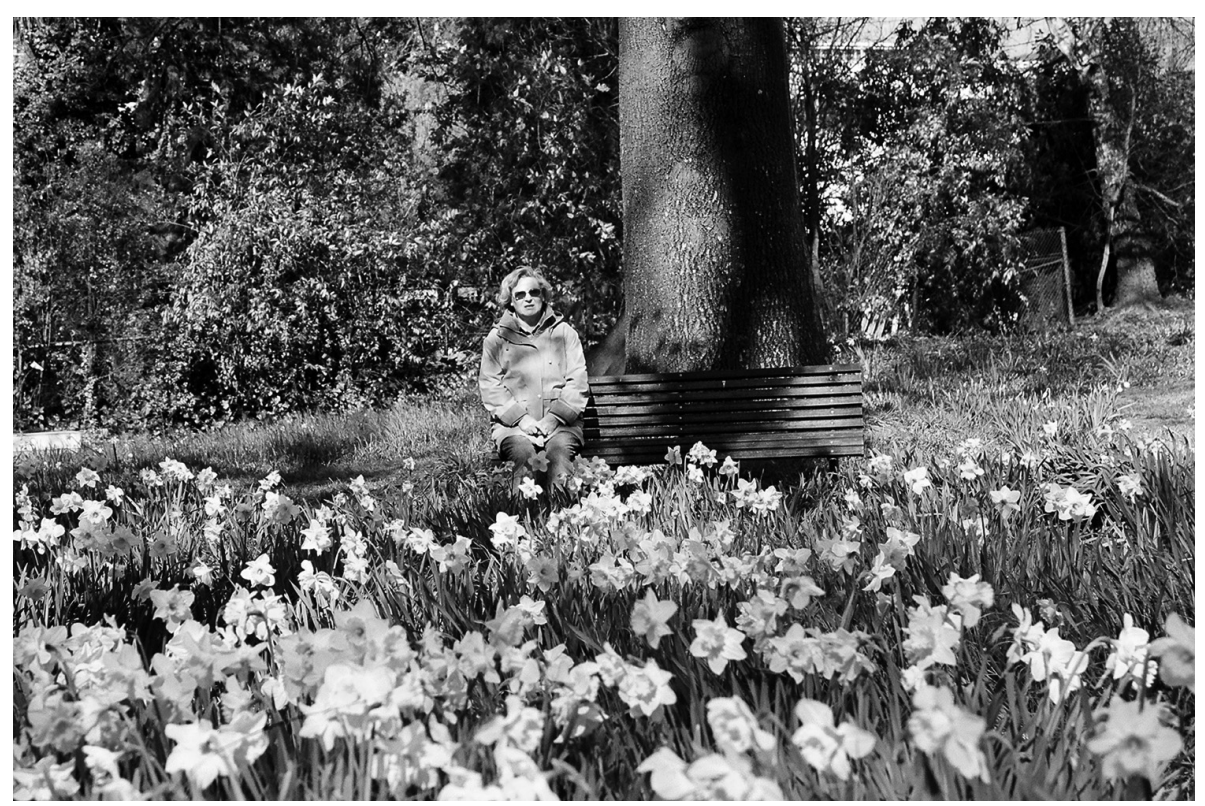

Fig. 23.6. Influence of Robinson's 'Wild Garden' in Christchurch, NZ Hagley Park (note daffodils).

tried to organise small naturalised groups of blooming rhododendrons that would look very 'natural' and beautiful. Robinson's practice of introducing native and exotic bulbs in woodland and grassland resulted in the appearance in new colonies of the same species in public and private gardens. For example, in Christchurch's Hagley Park in New Zealand, the display of daffodils and bluebells (Fig. 23.6) is one of the major city attractions in the spring. According to our recent survey of three neighbourhoods in Syracuse, New York, in private gardens, daffodils and tulips are still the most popular spring decorative cultivated plants. Gertrude Jekyll used classical perennial border plants such as Delphinium, Lavandula, Rosa, Dianthus, Campanula and Alcea rosea, and they can be found in practically every private colonial temperate garden.

\section{Urban habitats today}

The use of similar urban design structures, landscape architecture styles, plant material and construction materials has resulted in the creation of cities and towns around the world that have the same general appearance. For example, brick, sandstone, limestone, marble, concrete and granite are used for foundations, columns and steps, while asphalt is commonly used for roads and 
car parks. The use of gravel and mortar-joined material in cities and towns has resulted in the creation of specific urban biotopes (habitats) such as lawns, hedges, woodlands, flowerbeds, herbaceous borders, roadside and railway verges, walls and paving cracks (Breuste, Chapter 21). There are also remnants of natural vegetation that can be viewed as another type of urban habitat (Florgård, Chapter 22). Here we discuss several of these urban biotopes.

Lawns

Lawns are one of the most frequent and widespread urban biotopes (Muller, 1990). Lawns are found in parks, private gardens, playing fields, golf courses, along streets and roads, in plazas and schoolyards. In European parks, for example, lawns normally occupy between $75 \%$ and $95 \%$ of the park area (Gilbert, 1989). Lawns are nearly universal in front and back yards in suburban USA, Australia and New Zealand. For example, lawns average $52-80 \%$ of residential greenspace among ten older to newer neighbourhoods studied in Syracuse, New York (Richards et al., 1984). In Christchurch, New Zealand, lawns typically cover at least $50-60 \%$ of private gardens, and as much as $75 \%$ of public parks.

The first lawns were probably well maintained fields in Europe used for grazing cattle and sheep, but were also used as a setting for ornamental trees and shrubs. The origin of the lawn as a landscape feature is most likely due to the fact it occurs in natural European landscape as floodplain meadow vegetation. Lawns probably first appeared in the thirteenth century (Muller, 1990; Goryshina and Ignatieva, 2000) but the precise time of their appearance is unknown. In Medieval gardens a turf 'cut from good (meadow) grass' was used quite widely (Thacker, 1979).

Lawn was part of the English colonists' 'luggage' that they brought to new land, 'something domestic, or at least domesticated' (Teyssot, 1999). Lawn in former colonial private gardens and public parks symbolically represented the pastoral nostalgia of the English landscape. Domestic green 'carpet' was also a continuation of the interior of a house, explaining perfectly why lawn is supposed to be neat and tidy in all domestic gardens. In public spaces lawn always symbolised civic identity and democratic stability (O'Malley, 1999). One of the latest and very common theories to explain this 'passion' and love for lawns is the evolution of humans in the grassy, tree-scattered savannas of Africa (Bormann et al., 2001).

Lawn as a type of meadow plant community was completely alien to native landscapes of the northeastern United States, Australia and New Zealand. In the northeastern United States there is relatively little native (or long-evolved) meadow community associated with upland areas of the naturally forested region, so any meadow or lawn community had to be composed primarily of 
introduced species, especially from regions where there is a much longer history of livestock husbandry than in the northeastern USA (where it is less than 400 years). In Australia and New Zealand there are quite a few grasses in native biomes, but all of them are endemic to these countries and had a very 'foreign' appearance compared with green European meadow grasses.

Nowadays lawn can be seen not only as a symbol of the British Empire but also as a symbol of Western Civilisation. Because of the dominant economical and political role of the USA, its inhabitants have successfully transported this 'lawn aesthetic' around the globe. In the USA itself, lawns cover 27.6 million acres, an area about the size of the state of Pennsylvania. Lawn maintenance is about a $\$ 30$ billion industry (Bormann et al., 2001). Lawn is the major source of pollution in American suburbia as a result of mowing and herbicide application.

Comparison of available data on temperate lawns (in Europe (Gilbert, 1989; Muller, 1990; Wiltshire, 1994), Christchurch, New Zealand (Ignatieva et al., 2000) and Syracuse, New York (M. E. Ignatieva, 2003 field data)) shows that in 'colonial lawns' exotic species completely dominate - Lolium perenne, Poa pratensis and Festuca rubra are the most frequent grasses. Among perennials other Eurasian herbaceous species can be found in almost any urban lawn - Trifolium repens, Plantago lanceolata and Prunella vulgaris.

European lawns are dominated by European or Eurasian species. There are some native plant species in Christchurch (16) and Syracuse (6) lawns but they are uncommon with normally only two or three at any particular site. As for the overall number of species, lawns can vary from five to six species in intensively managed lawns (using herbicides, fertilisers, regularly watering and mowing) to 10-25 in 'common' casually maintained residential lawns with a high diversity of low-growing herbaceous species. Lawns show not only homogeneity in cultural appearance ('green' as viewed from a distance), but also in structure (one layer cutting regularly) and in composition (domination of certain 'noble' grasses) in sown mixtures.

\section{Hedges}

Hedges are special habitats created by planting trees or shrubs in a line or in small dense groups a short distance from each other. There are both short and tall hedges, formal (cut) and informal types. Hedges can be found in urban private gardens and in public parks, along streets and roads. There are quite a number of tree and shrub species available for hedges, but there is a group of common species that have been used for centuries. In Europe the most common and 'oldest' species used for hedges are Buxus sempervirens, Taxus baccata, Cupressus sempervirens, Cupressus macrocarpa, Chamaecyperus lawsoniana, Fagus sylvatica, Carpinus betulus and Quercus ilex. In New Zealand traditional European, Asian and some 
American species are very common in urban landscapes including Photinia glabra, Camellia japonica, Cupressus macrocarpa, Chamaecyperus lawsoniana, Fagus sylvatica and Pinus radiata. Recently some of the evergreen native species have also become popular such as Olearia paniculata, Corokia cotoneaster and Pittosporum tenuifolium. In the northeastern United States Taxus cuspidata and Berberis thunbergii from Asia, Ligustrum species from Europe and native Thuja occidentalis are among the most common species used for hedges. In Australia exotic plants are the most popular - Ligustrum species, Berberis thunbergii, Plumbago species and Buxus sempervirens.

Branches and trunks of trees or shrubs planted close to each other provide an excellent environment for the development of climbing species such as Convolvulus arvensis, Calystegia sepium, Galium aparine and Hedera helix. These plants can be observed in most hedges of European cities and in the colonies. The area at the base of the hedge under the canopy is usually bare ground or consists of a layer of mulch that is commonly colonised by weedy plants of Eurasian origin. Such plants as Elytrigia repens, Euphorbia peplus, Chenopodium album, Coronopus didymus and Taraxacum officinale commonly grow in these habitats.

\section{Flowerbeds}

The flowerbed is typically dominated by exotic herbaceous plants and occasionally sub-shrubs with decorative flowers or foliage. The species makeup of flowerbeds has always reflected the fashion of planting design. Nowadays the most popular summer bedding plants in public and private gardens are predominantly annuals derived from South Africa, Mexico and the Mediterranean. Floristic composition in former colonial cities is almost identical to the flowerbeds of European cities - Tagetes, Pelargonium, Petunia, Narcissus, Tulipa, Cineraria and Rosa. Flower borders in private gardens typically use a wider range of decorative plants. Among perennial exotic plants traditional English cottage plants are still popular and include roses, delphiniums, hollyhocks, peonies, lupins and lilies.

The most common spontaneous weeds of colonial flower borders are Euphorbia peplus, Sonchus oleraceus, Oxalis spp., Senecio vulgaris and Poa annua. A very important feature of this habitat is regular disturbance by cultivation, weeding, irrigation and fertiliser applications.

Pavement cracks and walls

Pavement cracks in all colonial cities have similar environmental parameters. First of all, plants that appear in cracks experience many stresses such as pollution from cars, extremes of temperature, compaction and trampling, and in some cases salt from de-icing (Woodell, 1979). The mechanical damage to 
plants and the compaction of soil lead to poor moisture retention and lack of aeration making pavement cracks a difficult environment for plants to survive. Because of the use of similar construction materials for buildings and roads and similar technology, the gaps between paving stones accumulate a similar soft soil-like substratum. Plants that occupy such habitats commonly do so in cities around the world. There are a lot of annual plants among 'pavement' plants. The four most common cosmopolitan species include Poa annua, Plantago major, Polygonum aviculare and Taraxacum officinale.

Brick, sandstone and limestone, concrete and granite are the most frequent materials for walls in most cities. The physical characteristics of mortar-joined materials for brick and stonewalls are very similar too. Similarity of environmental conditions such as moisture, light and temperature create conditions for growing similar plants. The Eurasian plant Cymballaria muralis is the most common urban wall plant around the globe. Some ferns are also very common among wall plants. For example, Dryopteris filix-mas has been found growing on many European and New Zealand urban walls.

\section{Searching for ecological identity in colonial cities}

Alternative or 'freedom lawns' in the Unites States of America

Many factors, including homogeneity of landscape, lack of natural biodiversity, air and soil pollution, and the use of fossil fuels associated with the creation and upkeep of lawns, the most common urban habitat, have resulted in a new interest in developing alternative solutions to traditional 'velvet' carpet lawns in America (Bormann et al., 2001).

The first and the oldest initiatives of an alternative to traditional lawns started around the turn of the twentieth century in the Midwest of the USA where the native 'prairie' grassland community was maintained and extended by wildfire. Jens Jensen (1860-1951), one of America's great landscape designers, created the 'Prairie Style' in landscape architecture. Instead of cultivating traditional exotic vegetation in tightly ordered patterns, he started to use native prairie plants in designed parks. 'Prairie school' architects used the Illinois tall-grass prairie and oak savannah as sources of inspiration. Jensen also encouraged the restoration of native landscapes along roadsides. At the same time Illinois landscape horticulturists pioneered the idea of using native plants and their natural plant associations, and the reintroduction of native plants in small yards as an alternative to traditional private gardening (Egan, 1990). Nowadays the Midwest is leading the USA in a number of projects in gardening with prairie plants in urban and suburban communities (Wasowski and Wasowski, 2002). 
With growing environmental awareness and ecological education over the past two decades, many Americans have begun to question the environmental and economic costs, and aesthetic quality, of the traditional lawn. New terms such as 'alternative lawns' and 'freedom lawns' have started to be used in popular gardening and scientific literature. Publications such as Michael Pollan's Second Nature (Pollan, 1991), Redesigning the American Lawn (Bormann et al., 2001) and The Lawn: A History of American Obsession (Jenkins, 1994) recount many stories of how ordinary Americans over the country have rethought their front and backyard designs and transferred their conventional lawns into prairie gardens, natural or wildlife gardens in the Midwest and northeastern USA or 'xeriscape' in dry areas throughout the country.

There are numerous publications available in the US landscape design and horticultural literature dedicated to landscaping with native plants (Diekelmann and Schuster, 1982; Stein, 1997; Knopf et al., 2002). Brooklyn Botanic Garden is the leading institution on this topic (Sawyers et al., 1990; Marinelli, 1994). Over recent decades the number of nurseries specialising in propagating native plants has grown dramatically. Today Americans can easily order cans of wildflowers.

There are also disadvantages of using 'alternative lawns', such as the fire hazard and insect problems, and also the occurrence of deer ticks which carry Lyme disease in some areas of the United States. The potential health risks are a concern to homeowners and have been widely discussed in local newspapers. Nevertheless, in most cases there are ways to eliminate such disadvantages using appropriate ecological design.

Unfortunately the average numbers of non-traditional native gardens in urban areas are still very low. For most people 'messy', unkept-looking 'freedom lawns' are associated with neglected landscapes. This is just the beginning of a change in traditional lawn psychology of conservative Americans towards sustainability and native biodiversity in urban landscapes.

'Go wild' in Europe

In the United Kingdom a new environmental movement towards increasing native biodiversity through designing with native plants is having real visible results. A dramatic decline of native habitats in the country forced a search for alternative ways to enhance native biodiversity. Today $20 \%$ ( 1 million acres) of urban areas in Great Britain are private gardens and they have the greatest potential for serving as new nature preserves. There is a large campaign in the country to increase native biodiversity by minimising traditional lawn areas and planting native plants that attract butterflies, insects and birds. In 2003, an exhibit called 'Go Wild', in Kew Botanic Gardens, illustrated ways of increasing urban biodiversity (butterflies, insects and birds) (Fig. 23.7). Among 


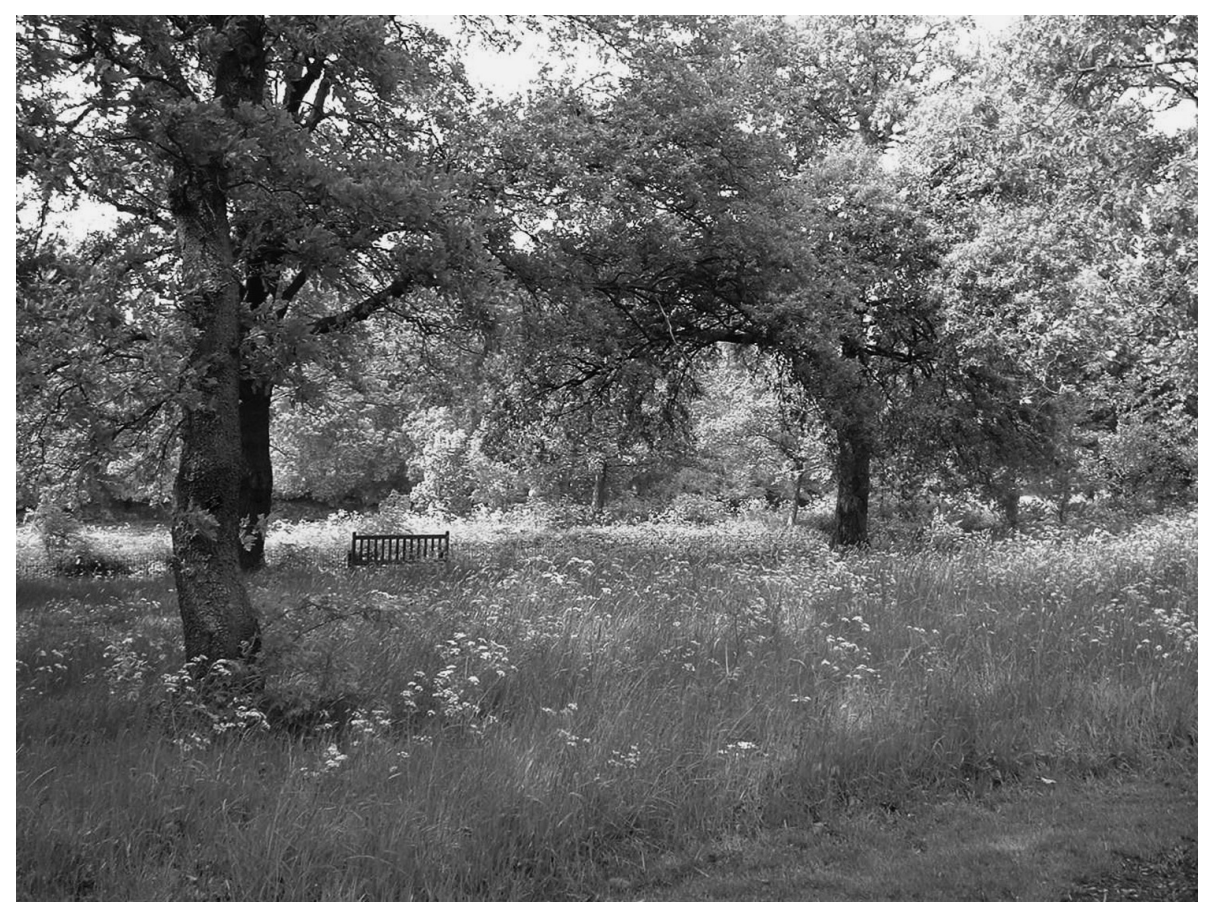

Fig. 23.7. 'Go Wild' exhibit where lawn was not mown and looks like a meadow. Royal Botanic Gardens, Kew, UK, in May 2003.

other European countries, the Netherlands and Germany have also been successful in designing with native plants in urban areas.

Towards a new individual ecological identity: plant signatures in New Zealand and Australia

Southern Hemisphere cities found their own way of breaking homogenous urban patterns and searching for a new way of creating an ecological as well as cultural identity. For Australia and New Zealand the concept of 'wild lawn' is not appropriate, because there is no native meadow vegetation (similar to traditional European) in the natural landscape. New Zealand and Australia have natural tussock vegetation dominated by grasses but this type of plant community looks very different from European floodplain meadows or American prairies. European patterns in architecture, planning structure and landscape design have dominated Australian and New Zealand landscapes for over 150 years. Native vegetation has only survived in the form of remnant patches throughout urban landscapes.

In the 1970s the environmental movement in Australia and New Zealand resulted in a blooming interest in native vegetation, and design with native 
plants in combination with interest in aboriginal art and culture. Restoration of native plant communities along rivers and coastlines, and woodlands has changed the appearance of many Australian and New Zealand urban settlements. There is also a strong movement towards creating indigenous or native gardens in Australia and New Zealand (Gabites and Lucas, 1998; Snape, 2002; Wrigley, 2003).

In 1993, Nick Robinson introduced the new concept of the 'plant signature' (Robinson, 1993). Plant signatures express the essence of a place through plant composition. The novelty of plant signatures is in the use of native plants and their combination to express the character of a particular place, offering distinctive and memorable designs. Plant signatures are about using plant combinations not only for environmental improvement, for these plants are adapted much better to existing environmental conditions, but as a way of adding distinctive identity to a neighbourhood through the design of streetscapes, street intersections, public parks, private gardens and public plazas.

In Australia and New Zealand plant signatures are often combined with sculptural or architectural works expressing aboriginal culture. For example, in New Zealand, tussock grasses are combined with stone sculptures or gravel stones having direct references to Maori culture. Nowadays plant signatures are used as a special tool for expressing national identity. For example, groups of native plants have appeared next to the Australian Parliament in Canberra and the Art Gallery of New South Wales in Sydney and next to significant buildings in all cities throughout the country. In Wellington the 'Bush City' next to the Museum of New Zealand (Te Papa) celebrates and symbolises natural New Zealand vegetation (Hicks, 1998).

Today, many native plants have become very symbolic in urban landscapes. In New Zealand, for example, one of the most common native plant combinations is cabbage tree (Cordyline) with flax (Phormium) and tussock grasses. Plant signatures are much more visible in the urban landscapes of New Zealand and Australia than in North America. But the plant signature concept could also be applied in American cities. For example, in Syracuse (New York) for plant signatures we recommended the use of a combination of plants from diverse and colourful native edges and pioneer successional herbaceous plant communities to replace part of extended lawns. This would make the urban landscape more environmentally friendly and provide new design dimensions (Carter and Ignatieva, 2002).

\section{Conclusions}

Former colonial cities have remarkable similarities in their urban biotopes and landscape designs. Given their similar settlement histories this is 
perhaps not surprising. The similar grid system, principles of development of downtown and suburbia, the most influential landscape architecture directions (Capability Brown, Picturesque and Gardenesque), use of urban construction materials and technique, and similarity in using introduced plant species (European deciduous trees for example) have produced an array of urban habitats that are replicated around the globe. From urban lawns to hedges and vegetation in pavement cracks and walls, the compositional and structural similarity in urban biotopes is remarkable. But now, this spreading social and ecological homogeneity in urban environments is recognised as dangerous and ending in loss of native biodiversity and general local identity. New concepts in planting design such as indigenous or native gardens, 'plant signatures', 'Go Wild' and 'alternative' or 'freedom lawns' in the United States, the United Kingdom, Australia and New Zealand offer new hope in searching for ecological and cultural identity in the cities. 